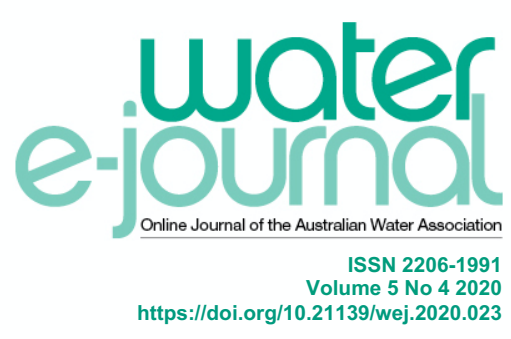

\title{
Working with Community and Council: The Kirirri Story
}

\section{Trialling water demand management strategies in the Torres Straits}

\section{ABSTRACT}

Ensuring safe, accessible and acceptable drinking water in remote communities in Australia requires culturally and socially appropriate, technically feasible and economically viable approaches. Arguably, technical and economic factors have been the main focus for remote communities in the water sector, as engineers historically drove the design, planning and construction phases of water supply management options.

More recently, increasing focus has been on understanding and integrating local people and place into water supply and demand management. This paper focusses on communitybased water demand management in the inner Torres Straits community of Kirirri. The aims and methods are outlined, along with a discussion of the findings which describe the community-preferred demand management tools that were piloted in 25 households between 20182019.

The paper concludes that individual household water use feedback and strengths-based community messaging are promising tools for achieving sustained outdoor water conservation behaviour.

\section{ACKNOWLEDGEMENT OF COUNTRY}

The authors would like to acknowledge the past, present and future Traditional Owners of the Kaurareg for giving us the right to work and speak on their land.

\section{INTRODUCTION}

Equitable access to acceptably treated drinking water is a fundamental human right. While many of us associate poor and inadequate supplies of drinking water with developing countries elsewhere in the world, there exist many remote communities in Australia that struggle to access safe and reliable drinking water (Hall et al 2020, Beal et al 2018). The reasons for this are complex and reflect the broader ongoing struggles to close the gap between Aboriginal and Torres Strait Islander people and non-Indigenous Australians.

Additionally, increasing essential service delivery challenges, borne from a changing climate, are threatening water security and the general health and well-being in remote communities. For example, in many Torres Strait Islander communities, there are severe water restrictions during the dry season (May to November) and this can result in the treated, piped water supply being physically turned off by the council for up to 16 hours a day (i.e. controlled access to the mains water supply) (Beal et al 2019). Town or mains water may be available between the hours of 6-9am, $12-2 \mathrm{pm}$ and $6-10 \mathrm{pm}$ (these times will vary throughout the year).

It is becoming increasingly clear that business-as-usual, Western technically-focussed solutions are not providing appropriate and genuinely sustainable technical, social or cultural solutions to remote community water management 'problems' (Frangos et al. 2020, Jackson and Moggridge 2019, Jackson et al 2019 a,b). The story, however, need not be all negative. The inherent strengths of a community can be harnessed to work toward greater sustainability and resilience of water supplies in remote First Nations communities. These strengths may be tangible or intangible, 
such as community cohesion, deep connections to land and water, storytelling, place-based solutions and custodianship (Frangos et al 2020, Buergelt et al 2017, Hill et al 2012). One first step toward this strengths-based approach is sincere engagement and collaboration between community members, water service providers (often local council in remote communities) and non-Indigenous organisations.

From a non-Indigenous researcher perspective, this is not always easy to do genuinely, over a long period of time, particularly in the political, short-term funding research cycle that researchers are frequently reliant on. Nevertheless, there are continued efforts to conduct research in a collaborative approach and this paper describes one such water project recently conducted in the Torres Strait Islands.

The community-based water demand management trial project on Kiriri (Hammond Island) was initiated by the Torres Strait Island Regional Council (TSIRC) as part of the larger Sustainable Water and Wastewater Management Project (SWWMP) undertaken in 2018-2019. The aim of this study was threefold: firstly, to understand how residential water is being used on Kirirri; secondly, to use these insights to trial some community-based water demand management (CWDM) strategies; and thirdly, to monitor and evaluate the trial to identify appropriate strategies.

\section{METHODS}

\section{Community context}

The Kirirri community is located in the traditional lands and seas of the Kaurareg people. The languages spoken in the community of approximately 250 residents is the Kalau Kawau Ya dialect and Torres Strait Creole (broken English). The community is located a short distance from Thursday Island, the main business hub of the Torres Straits, and is only accessed by boat or aircraft (Figure 1).

Kirirri's main water source is an earthen dam located on Horn Island that feeds a subsea pipe to Thursday Island, where it is then pumped (subsea) to the Water Treatment Plant on Kirirri. From here the water is fed through media filters prior to being chlorinated by an automated dosing system, and then stored in an elevated reservoir tank for distribution of treated water through the island's water mains network.

Water demand has been historically high on the island, particularly in the drier months (i.e. May - Nov), leading up to the wet season (around Dec - Apr) where daily use can range from 180 to 600 litres per person $(\mathrm{L} / \mathrm{p})$, with recorded monthly averages over $300 \mathrm{~L} / \mathrm{p} / \mathrm{d}$ (Beal et al 2019).

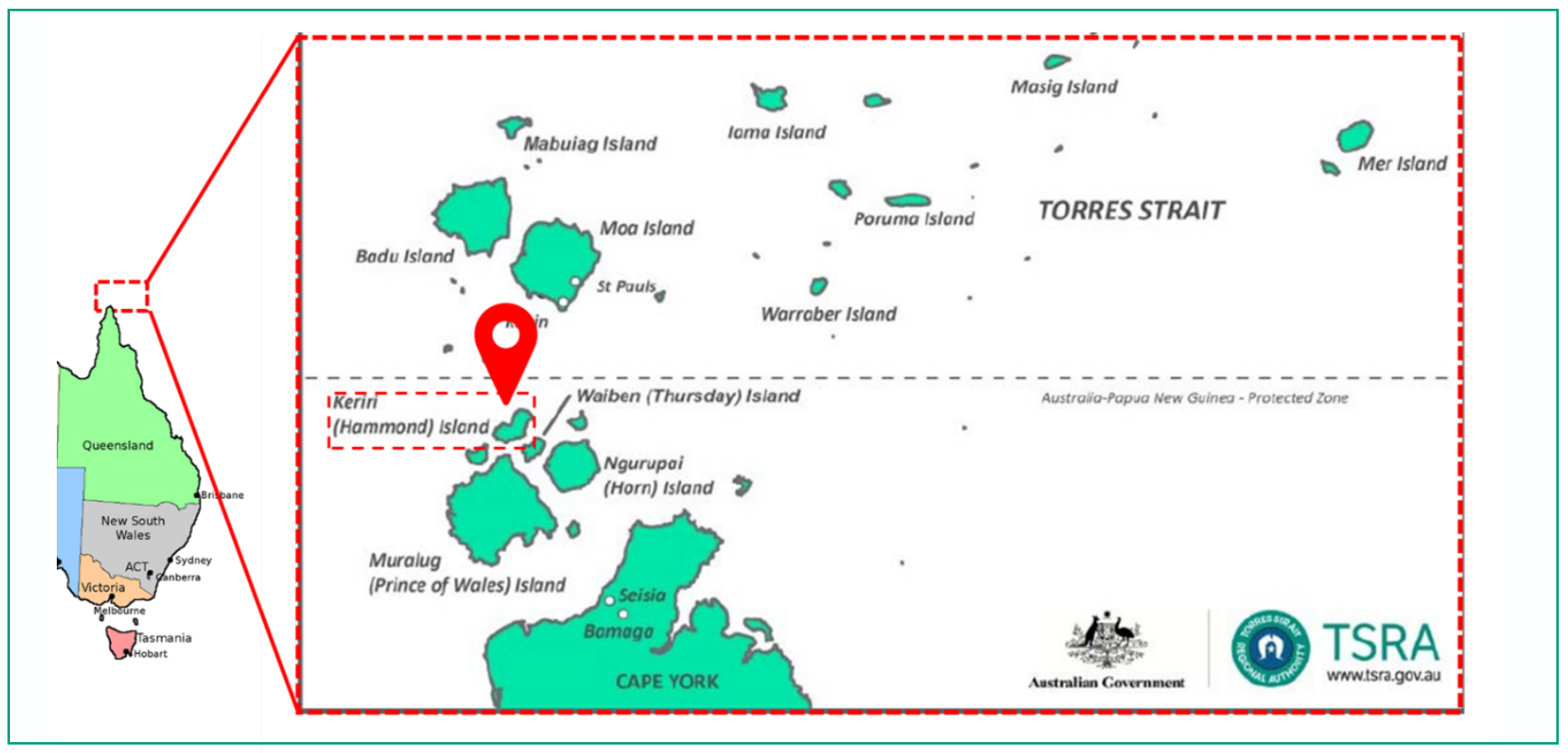

Figure 1. Location of Kirirri (Hammond) in the south-western Torres Strait region (Source: TSRA) 


\section{Household participation}

While it is acknowledged that the community itself did not instigate the project (which is the ideal scenario), the Kirirri residents were invited to participate on a voluntary basis. Options for engaging participants were discussed with the local TSIRC staff and community representatives. Initially, this was carried out largely by TSIRC officers, and subsequent visits by the Brisbane research team sought to confirm the participant's willingness through door-to-door introductions and informed consent signatures.

The project methods, including participant recruitment, survey methodology and implementation, and data generation, storage and management, has been reviewed by the Griffith University Indigenous Research Unit and cleared by the Human Ethics office (GU Ref No: 2017/936). Each household in the community, and their water and survey data, is anonymous and reported in a de-identified format.

A total number of 25 households volunteered to be part of the project. This represented approximately $32 \%$ of total households $(n=78)$ on the island. This is considered a statistically strong sample and enabled a good representation of the mix of family size and characteristics across the community.

\section{Data acquisition and analysis}

\section{Smart water meters and end-use disaggregation}

Residential-scale water consumption was monitored using high resolution digital water meters and loggers which were installed at 20 of the 25 participating households. The local TSIRC officers were trained in installing and initialising the Actaris meters which measure flow to a resolution of 72 pulses/L or a pulse every $0.014 \mathrm{~L}$.

The smart meters were connected to Aegis RX data loggers, programmed to record pulse counts at ten second intervals. Data was wirelessly transferred to a central computer and stored in a database for subsequent analysis. Using the high resolution datasets from the participating households, a sample of received data was extracted from the database for two, two-week periods selected to represent the wet and dry seasons, and disaggregated into all end use events (e.g. shower, clothes washer, tap, leaks, outdoor, bath, toilet) using the flow trace software Autoflow (Nguyen et al 2015).

End use analysis was based on a continuous two-week period chosen based on the weather patterns and overall water use of the participating households. These dates were chosen to identify the type of end-uses that are influencing water demand for both low (below average) and high (above average) water consumption periods during the wet and dry seasons, respectively.

Concomitantly with meter and logger installation, a water fixture/appliance stock (e.g. clothes washer, toilet, shower) survey was conducted at each participating home which facilitated the disaggregation of trace flows from each home and also provided a valuable snapshot of water consumption practices within each home. More details on the smart metering and data analysis aspects of the project can be accessed from Beal et al (2019).

\section{Local perspectives of water}

An essential component of the research approach was obtaining qualitative data through face-to-face, two-way engagement with the participants and wider community. Informal discussions that focussed on 'listening and learning', rather than 'talking and telling' enabled deeper insights into the behaviours, attitudes, concerns and challenges that the local community face with respect to their water supply (quality and quantity).

By obtaining this information we were able to have a better understanding of local community perspectives, which is critical to developing a balanced water management strategy that can incorporate a community voice and potentially more likely to be implemented by the community.

The water-related questions were designed to understand the existing uses of water by each household, as well as the knowledge and attitudes of different water users, and the ability and opportunities they had to conserve water. Questions were designed for the following categories of information relating to water demand management: water consumption; water values and behaviours; and attitudes toward community water security.

\section{Community-based water demand management trial}

Based on participant and local council feedback, five 'tools' or strategies were developed to trial (Table 1). The key steps of the community-based water demand management (CWDM) trial are shown in Figure 2. These included: 1) smart meter enabled baseline water use characterisation; 2) individual feedback of water use (Figure 3); and 3) co- 
designing CWDM strategies with participants and council (Figure 4).

Monitoring and evaluation of the CWDM was undertaken using qualitative and quantitative approaches including smart metering data, informal surveys and key informant interviews. Participants from each household provided structured and non-structured feedback on the CWDM trial (evaluation of trial/project process itself) and on future CWDM strategies that could be used specifically for TSIRC communities.
Key informant interviewees were people specifically chosen to provide more in-depth insights into 1) water management on Kirirri (and the wider TSIRC region); 2) the CWDM trial evaluation; and 3) culturally and socially appropriate CWDM strategies for future demand management programs.

Table 1. CWDM tools that were used in the trial on Kirirri

\begin{tabular}{|c|c|}
\hline CWDM tool & Activity \\
\hline 'Smart' water meters & $\begin{array}{l}\text { Existing standard water meters were substituted with higher resolution water meters in participating households. } \\
\text { A total of } 20 \text { smart meters were installed. }\end{array}$ \\
\hline Water use feedback & $\begin{array}{l}\text { Pie charts of individual household water use (per person and per household) were created from smart metering } \\
\text { data and were shared with all participating project households. }\end{array}$ \\
\hline $\begin{array}{l}\text { Benchmarking of household } \\
\text { water use }\end{array}$ & $\begin{array}{l}\text { A comparison of individual household water use (per person and per household) with the average of all } \\
\text { participating households in each community were provided to households. }\end{array}$ \\
\hline Education \& awareness & Discussion on water conservation tips and efficient use of water outdoors. \\
\hline Water-efficient devices & $\begin{array}{l}\text { Simple and inexpensive water-efficient outdoor devices were provided to the project participants e.g. manual tap } \\
\text { timers. }\end{array}$ \\
\hline
\end{tabular}

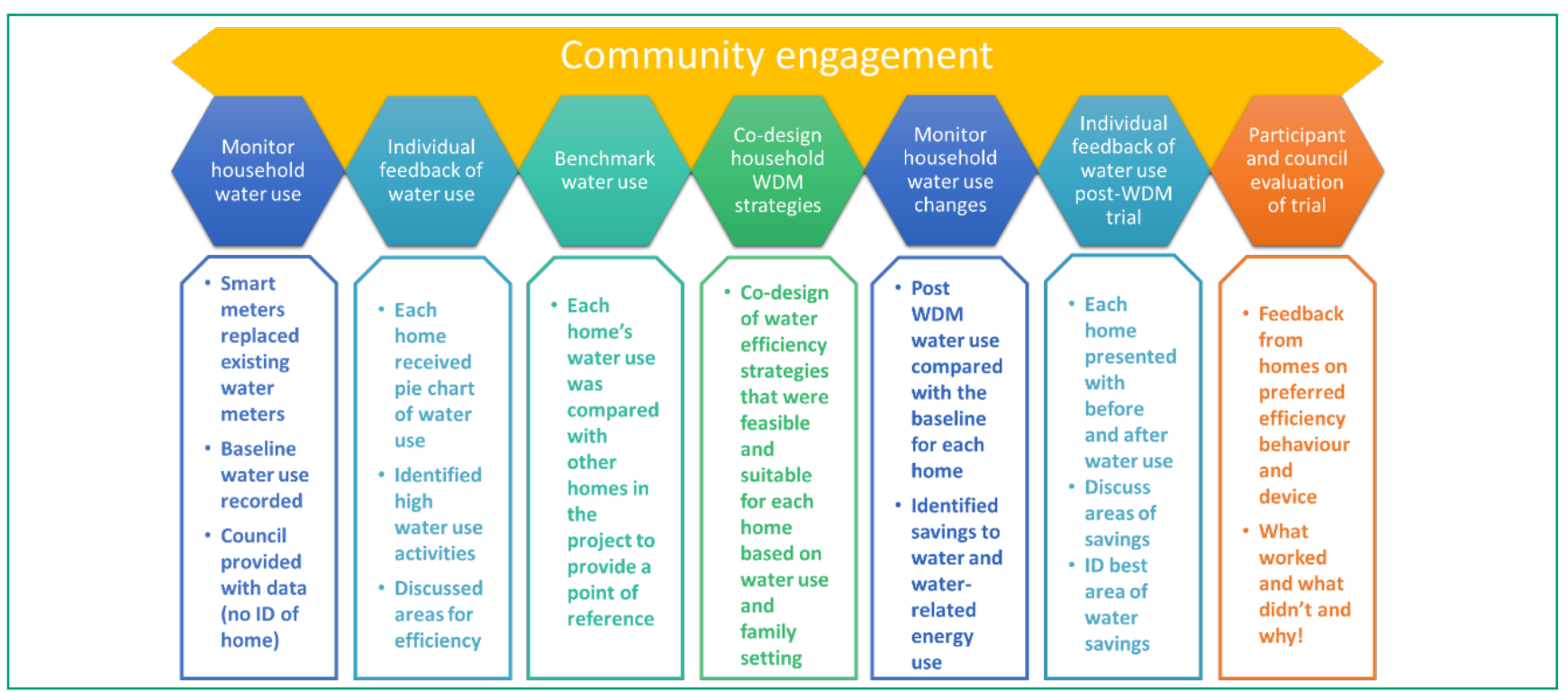

Figure 2. Key steps in the CWDM trial 


\section{Community Engagement}

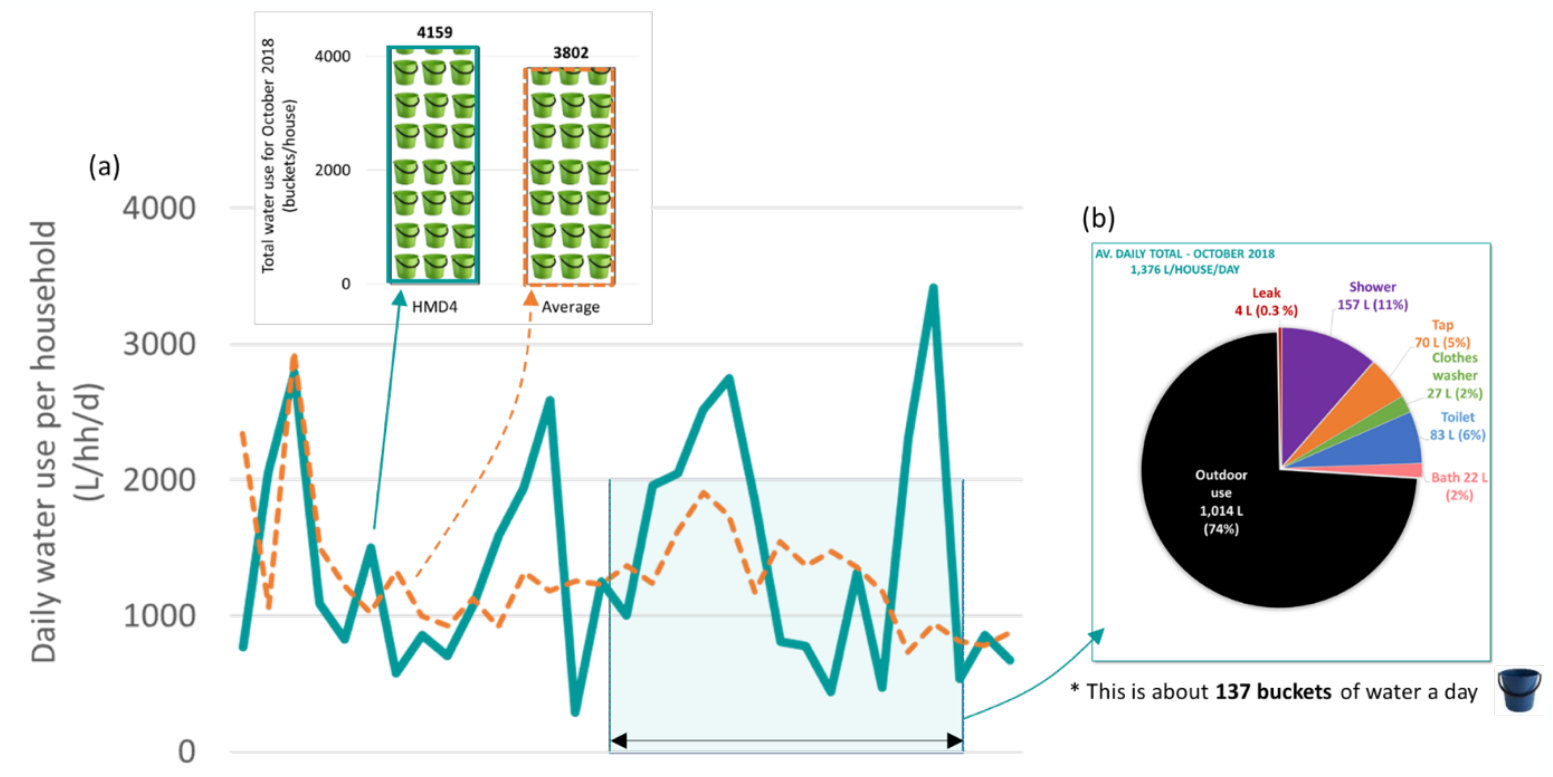

Figure 3. Example of individual feedback to each participating home showing a) total water use and b) end-use categories

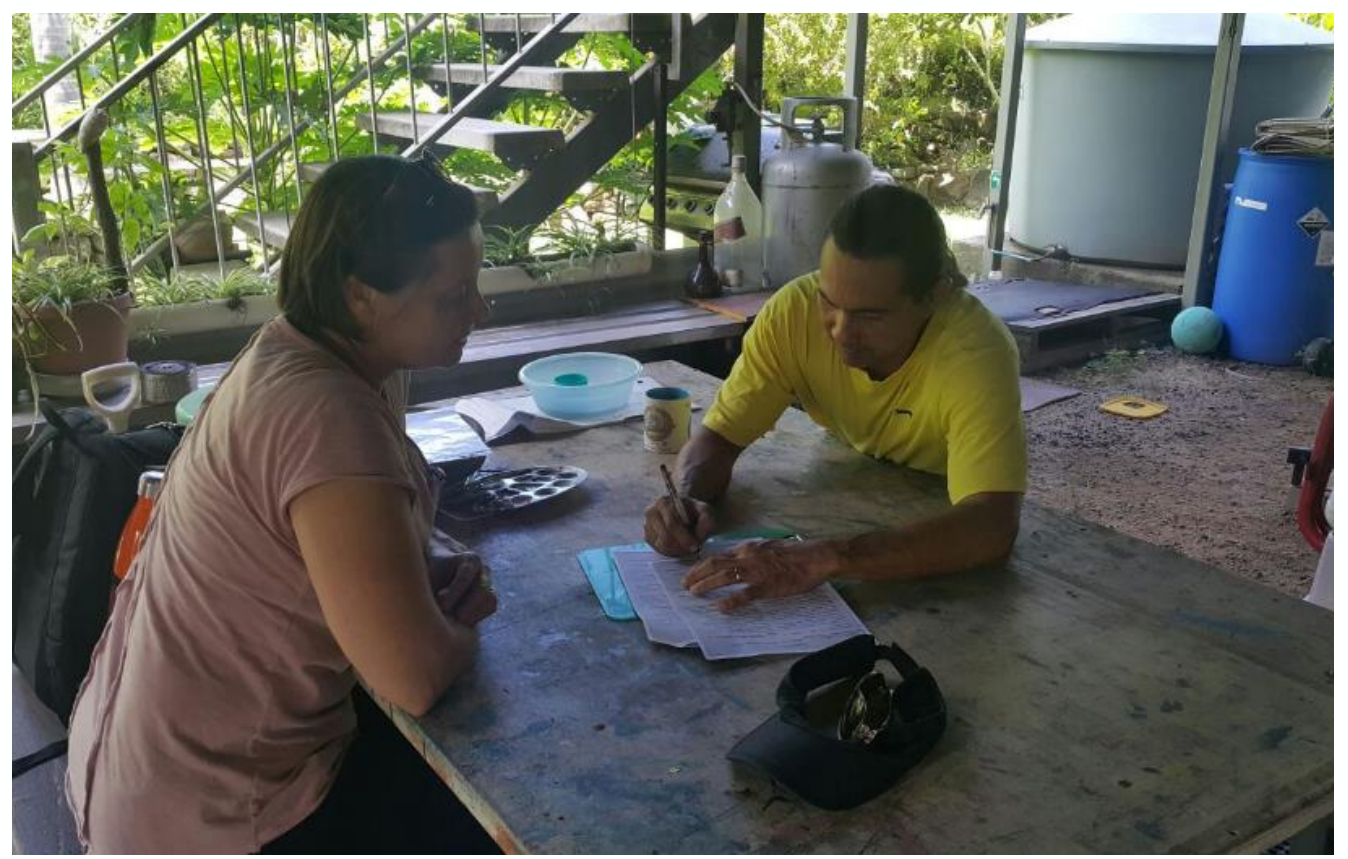

Figure 4. Discussing CWDM strategies suitable for Kirirri community (photo used with permission) 


\section{CHARACTERISING BASELINE WATER CONSUMPTION}

Daily per household water use for the period 30 May 2018 to 31 March 2019 ranged from 0 to 26,520 litres per household per day $(\mathrm{L} / \mathrm{hh} / \mathrm{d}$ ) and the average was $1,000 \mathrm{~L} / \mathrm{hh} / \mathrm{d}$ (with a standard deviation of $\pm 1,647 \mathrm{~L} / \mathrm{hh} / \mathrm{d}$ ). The median water use for the whole period of monitoring was $617 \mathrm{~L} / \mathrm{hh} / \mathrm{d}$.

Daily per person water use for the period 30 May 2018 to 31 March 2019 averaged $199 \mathrm{~L} / \mathrm{p} / \mathrm{d}( \pm 99)$ with a maximum daily average use of $626 \mathrm{~L} / \mathrm{p} / \mathrm{d}$ (Figure 7 ). The median water use for the whole period of monitoring was $179 \mathrm{~L} / \mathrm{p} / \mathrm{d}$. It is important to note that per person water use is based on the number of people permanently living in each of the participating households. The number of residents was determined during the initial household surveys and rechecked during follow up site visits.

It is useful, perhaps essential, to consider both per household and per person water consumption patterns when assessing (and forecasting) water demand and also when developing demand management strategies, particularly in Aboriginal and Torres Strait Islander communities where household occupancy can be high and transient. This may be especially pertinent for determining outdoor water demand.

For example, in a large occupancy household, an outdoor per capita water use of $50 \mathrm{~L} / \mathrm{p} / \mathrm{d}$ may not seem excessive, but if this equates to $400 \mathrm{~L}$ on a per household basis, then this is less sustainable, particularly during water restrictions or dry weather periods where water security becomes more of an issue. Furthermore, individually tailored demand management messaging may not be triggered in homes where outdoor water consumption is assessed on a per person basis.

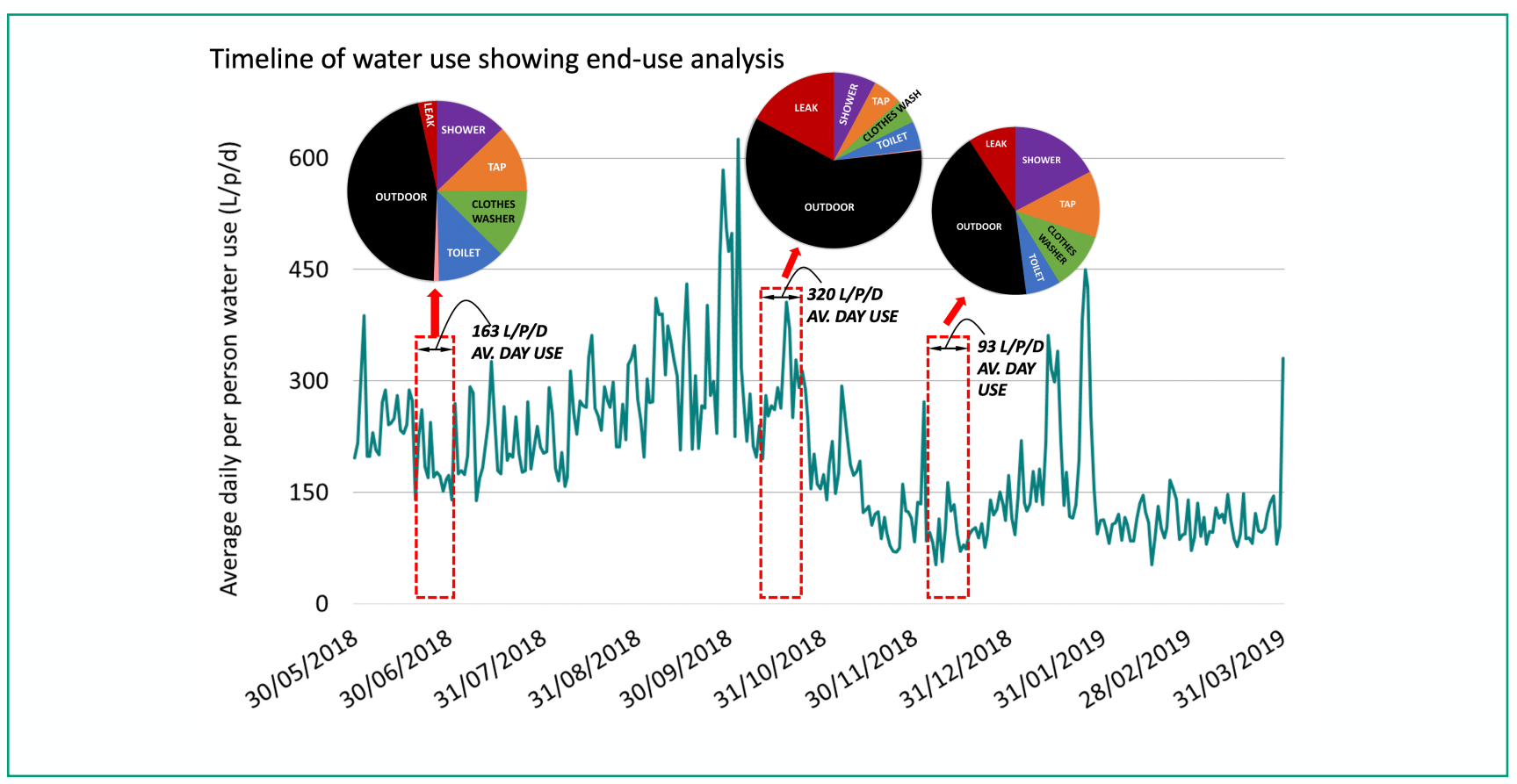

Figure 5. Average per person daily water use consumption trend

Note for Figure 5: Per capita average daily water use was calculated by the total daily water usage from number of metered households included in each analysis period divided by total population of households included each analysis period. This method accounts for the different household populations which did vary depending on which households were included in the end-use analysis. Obviously, ideally all 20 households would have been included in each end-use period but due to data collection issues which continued throughout the project, the number of homes changed (reduced) over time and thus the total number of people also changed. 


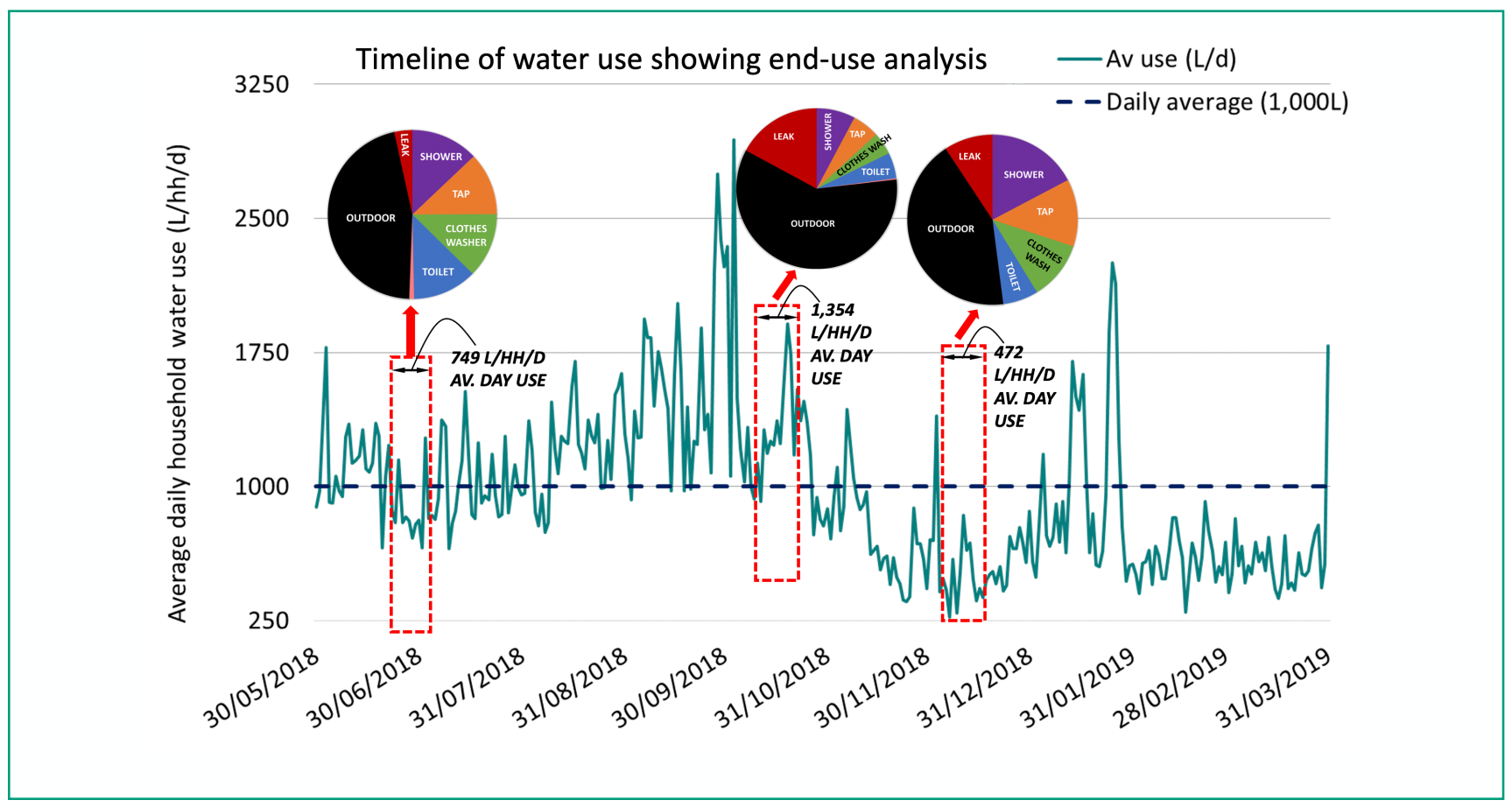

Figure 6. Average household daily water use consumption trend and end-use breakdowns

The end-use pie charts show outdoor use (black wedges) remains a 'hotspot' area for targeted demand management. This has been demonstrated previously (Beal et al 2019, 2018). Indoor water use remained relatively homogenous across time with large leak events (red wedges) at two homes influencing the total end-use trends in October (this leak was not prolonged).

\section{KEY FINDINGS FROM THE CWDM TRIAL}

During the CWDM process, various demand management strategies were discussed, and barriers and enablers pertaining to demand management strategies were identified. These have been discussed by Aldirawi et al (2018). Following on from this, a number of CWDM tools were then implemented on Kiriri and subsequently evaluated using quantitative (smart meters) and qualitative (surveys/key informant interviews) methods.

\section{Quantitative (water use) evaluation of the CWDM trial}

Based on the smart meter data, water use from participating homes in the project reduced from $256 \mathrm{~L} / \mathrm{p} / \mathrm{d}$ on average pre-CWDM trial down to an average of $131 \mathrm{~L} / \mathrm{p} / \mathrm{d}$ (Figure 8). The inset of Figure 8 also shows the substantial reduction in water use across all end uses, but particularly outdoor (which was targeted in the trial). While this is a good result on its own, unfortunately there were some confounding factors that make unambiguous attribution of the CWDM tools to water reduction difficult.

Firstly, water restrictions commenced (unbeknownst to the researchers) around the time of the introduction of the trial on 12-16 November 2018. This would have had some impact on the volume of outdoor water use measured by the smart meters, but it is very difficult to isolate the influence of the introduction of the water restrictions with the influence of the CWDM measures. When asked, the local TSIRC officers were uncertain when the water restrictions were lifted by Torres Shire Council but estimated it to be in the New Year (2019) 
The other confounding factor is the beginning of the wet season, with rainfall events recorded from 7 December and continuing sporadically through to late March. Rainfall is not always strongly correlated to a reduction in residential water demand, but water use patterns from other data from aligned projects (e.g. work with Masig community, see Beal et al 2019) suggest that water use will drop in general over the summer.

Due to the limited timeframe and budget of the project, there was little option to continue the trial for another 12-month cycle, which would have been preferable to address some of the limitations. Nevertheless, the trial did provide useful insights, for example, it is likely that the implementation of CWDM strategies, especially the use of tap timers, has impacted (lowered) water demand for the participating households in the project. This was reinforced through qualitative measures during the evaluation phase.

In reality, a successful CWDM approach does not rely on only one or two tools or strategies, but delivers a suite of actions. These could include council directed ones, such as water restrictions and council feedback to households on their water use, and community-led ones, such as using tap timers, checking leaks, and generally committing to using water more efficiently. The CWDM trial highlights how different approaches can positively impact on water use with a $42 \%$ reduction in water use from participating households being recorded.

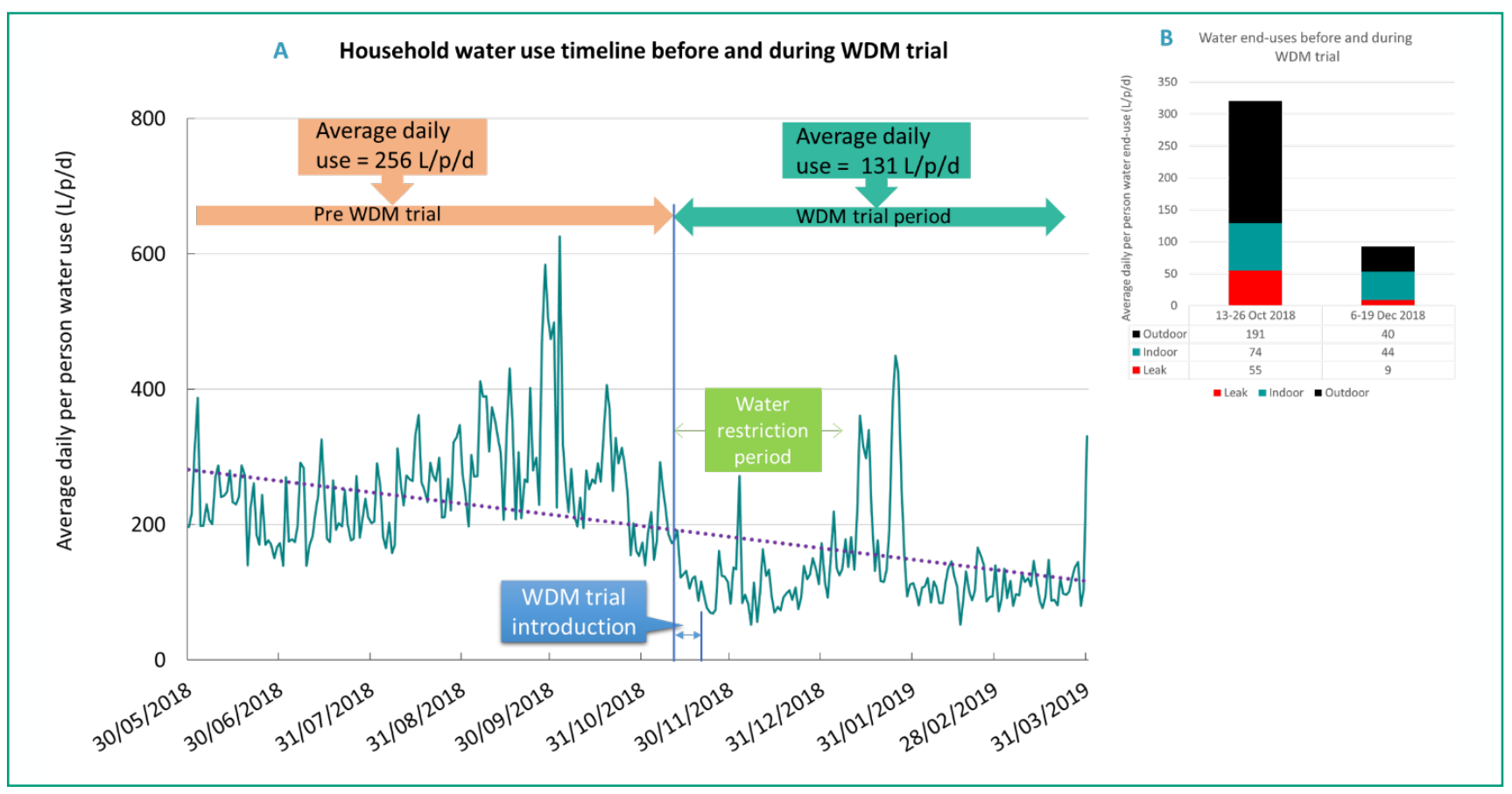

Figure 7. Water demand timeline August 2018 to March 2019 showing CWDM trial 


\section{Qualitative evaluation of the CWDM trial}

From analyses of the survey responses, participant discussions, water end-use analysis and council consultation it emerged that several key drivers were contributing to the observed high outdoor water use activities (Beal et al 2019).

Following baseline analysis, further discussions were held with all participants about their individual water end-use breakdown activities and to identify more specifically the drivers (i.e. reasons and motivations) behind their high outdoor water use. The identified drivers of high outdoor water use are closely linked to necessary day-to-day functioning e.g. health (dust control suppression, house and personal cooling, food preparation, cleaning dusty verandas and windows, boats and hunting and fishing equipment) and well-being (group celebrations and festivities, tombstone openings, sorry business, children's play, watering gardens, trees and establishing ground cover).

The qualitative evaluation offered another angle with which to gauge the impact of the CWDM trial on Kirirri. A number of questions were posed around the usefulness and likely long-term engagement with each CWDM tool used in the trial. Feedback of actual water consumption data and benchmarking of individual household water use with others in the community scored very highly as favoured demand management tools (Figure 8). As one participant said: "This is the first time someone has actually given us some idea of how we use water and ways we can save water...not just telling us to stop using it" (Participant and Kirirri Traditional Owner).

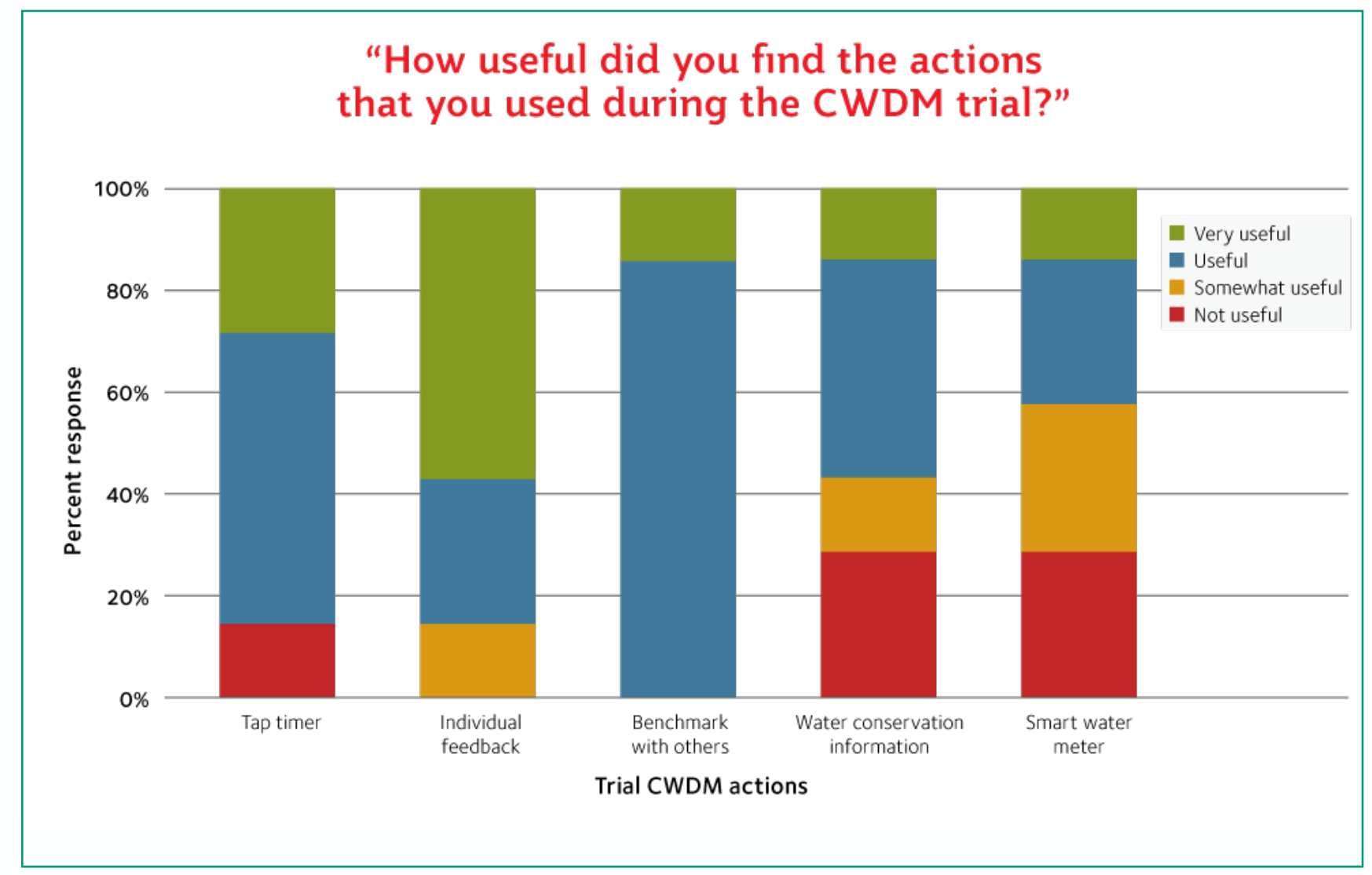

Figure 8. Household participant responses for trialled CWDM tools 
In general, participants identified a greater likelihood of longterm engagement with outdoor-based water conservation actions relating to communication and engagement rather than physically using less water or using a water-saving device (Figure 9). Others have found that less focus on devices and more emphasis on education stories and twoway communication to be more effective for demand management (Buergelt et al. 2017).
There was a reluctance to reduce the actual watering of plants and gardens for several reasons with responses including: "...gardening is important to me"; "will water twice a day....am starting my garden"; and "...yes [will reduce watering] in the wet season, but in dry season I will keep watering".

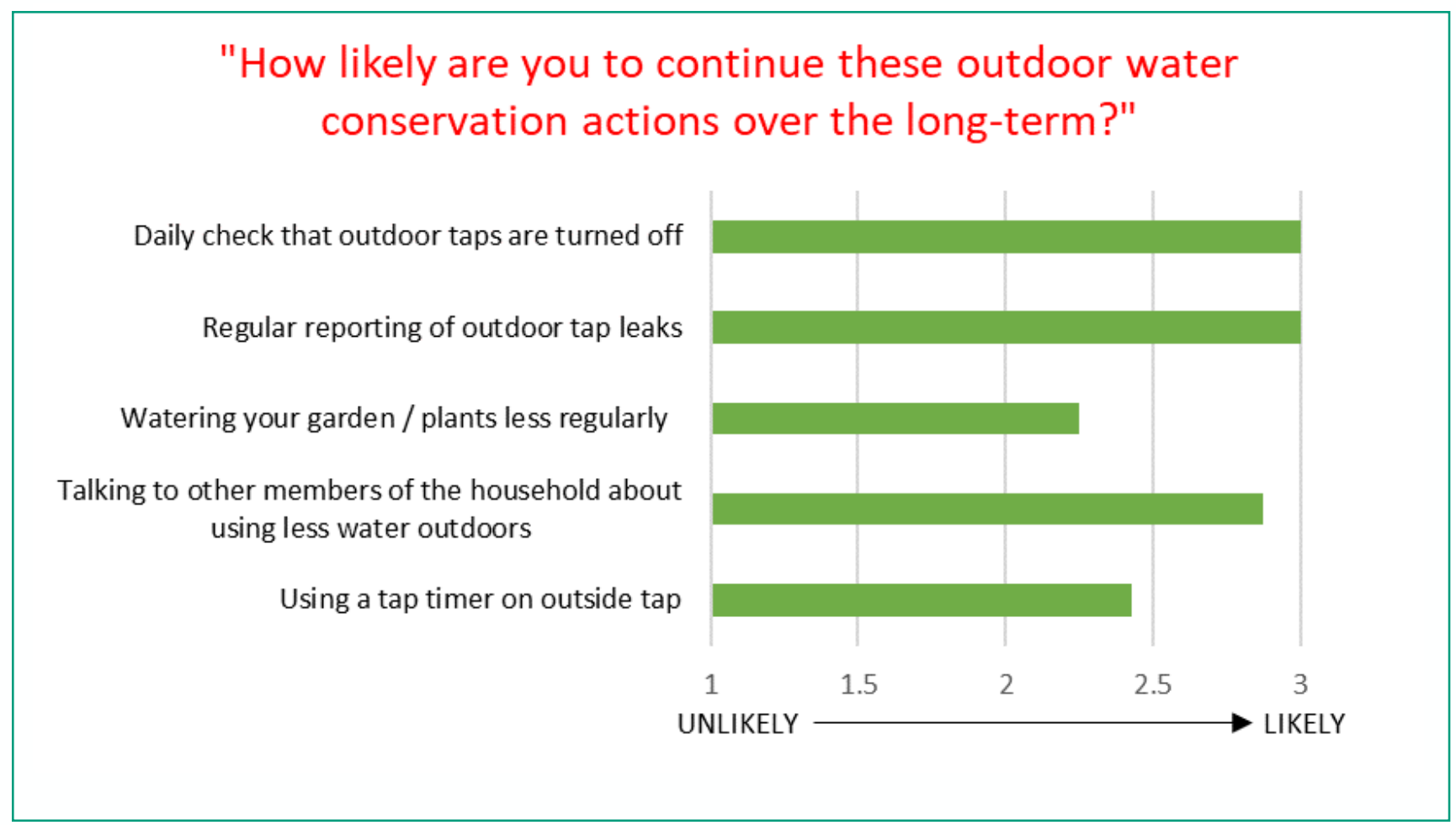

Figure 9. Low versus high water comparisons on likelihood for future CWDM tool engagement 


\section{Evaluation of a suite of CWDM strategies for TSIRC communities}

Along with the actual tools/actions that were trialled, a range of CWDM management strategies (that were identified during a separate consultancy-led council workshop as part of the SWWMP) were proposed to the participants to determine which strategies they would consider more useful than others. Results from this section of the evaluation survey were analysed based on council versus non-council respondents (Figure 10).

In general, TSIRC officers believed a broad range of CWDM approaches would be useful for implementation across all TSIRC communities, although they were less convinced that community workshops ("no-one would turn up") would be a tool that would be likely to work. Conversely, non-council project participants felt that community-based strategies would be more likely to work. These included school programs, community workshops and social and traditional media community announcements.

In general, compared with council survey participants, noncouncil survey participants were more circumspect about the likelihood of some of the proposed strategies working, especially the more punitive-based ones such as charging high water users, shower alarms, household alarms, public reporting of high water use and enforcing permanent water restrictions.

Inter-island competitions that aim to generate a friendly rivalry to see which island can achieve the lowest water use, was generally received well from both council and noncouncil project participants. It was however, consistently pointed out that this would only work if the competition was divided into inner and outer islands to make it fairer competition. For example, the outer islands, where they have their mains water turned off for several hours a day, should have their own competition to reflect the 'easier' conditions to save water.

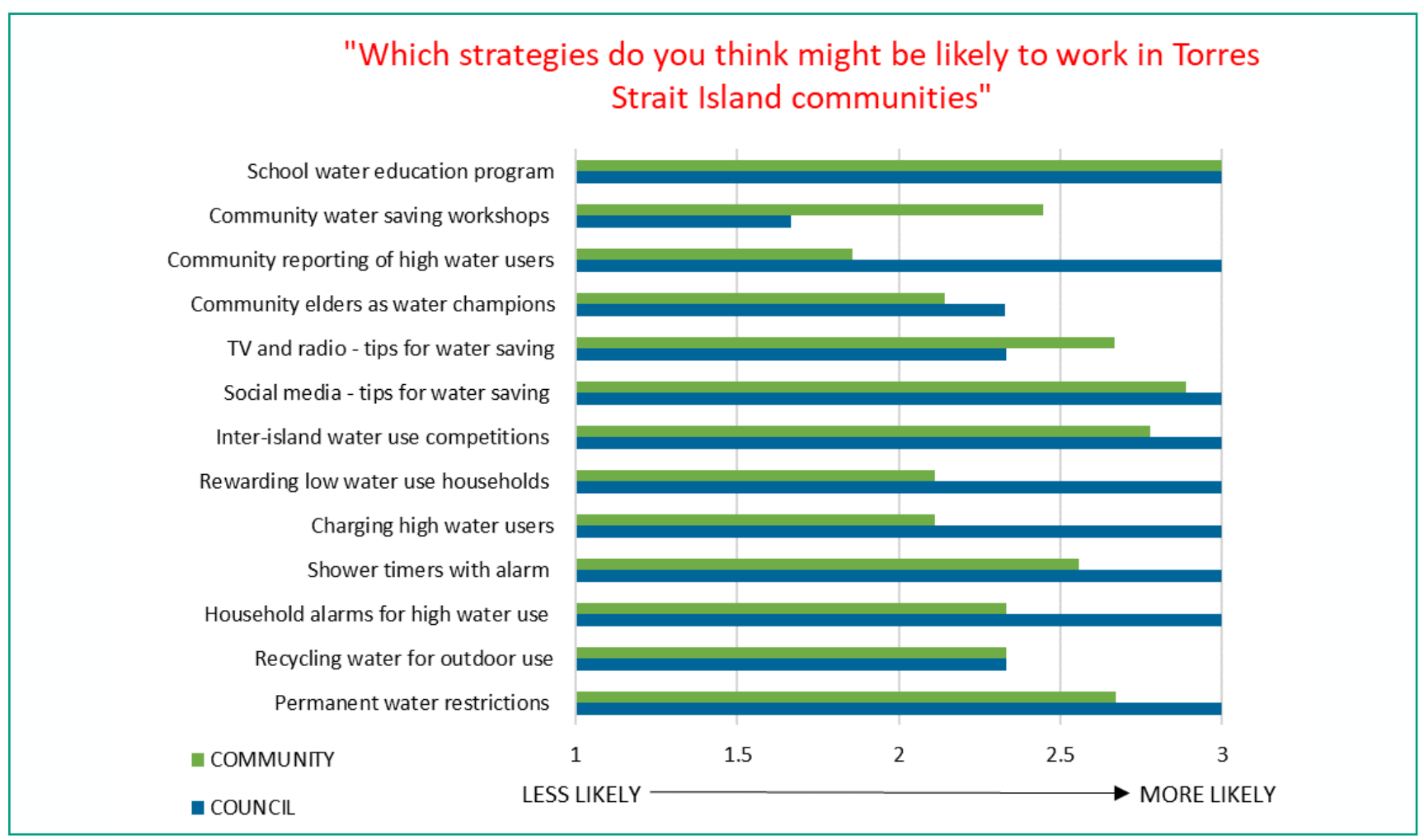

Figure 10. Perceptions of the success of a range of CWDM strategies in TSIRC communities 


\section{DISCUSSION}

Drawing on the insights gained from the project participants, a range of CWDM options were ranked (out of a potential score of three) in order of preference and suitability by all project participants (Table 2).

It is important to consider that different demand management approaches offer different levels of "effectiveness", i.e. short-term versus long-term impacts to water consumption and thus overall water supply security.

Previous research in this area suggests that long-term gains from demand-side approaches that target a permanent change in behaviours, including on-going community engagement and encouragement, are as least, if not more in some cases, effective as the more costly engineering approaches (e.g. Beal et al 2016; Tortajada \& Joshi, 2013; Walter and Hume 2011; Russell and Fielding, 2010).

Most of the CWDM strategies listed in Table 2 have been discussed with the project participants, with some trialled (shaded in blue). Both council and non-council participants have generally given the "green light" in terms of the likelihood of community engagement with the strategies and the perception of the strategies being at least somewhat useful and acceptable for the Torres Strait Islander culture and lifestyle.

Not all of the CWDM strategies in isolation would work with all households in the community, but in combination, there is much more likelihood of a long-term engagement. In general, CWDM activities that involve feedback of household water use, education and encouragement around how, why and when to save water, were popular with the participants and were also relatively low cost.

Feedback for water use, and benchmarking with other households, can still be done without smart meter water data, but this would require a bit more training and effort though still at a generally low cost.

The project findings revealed some mismatches or disparities between council and community perspectives on the importance of water conservation and the approach to water savings in the community. This is a crucial factor in the success of CWDM as shown in Table 2, where both council and community will take lead roles (formally or informally) for various strategies.

\section{Table 2. Ranked CWDM strategies}

(NOTES: ${ }^{1}$ council (CL), community (CM); ${ }^{2}$ either trialled in project (shaded blue) or raised in participant surveys; ${ }^{3}$ averaged from all respondents.

\begin{tabular}{|c|c|c|}
\hline $\begin{array}{c}\text { Who } \\
\text { leads? }\end{array}$ & WDM strategy ${ }^{2}$ & $\begin{array}{l}\text { Overall } \\
\text { rank }^{3}-1\end{array}$ \\
\hline $\mathrm{CL}$ & $\begin{array}{l}\text { Benchmarking /Comparison of } \\
\text { household water use with others }\end{array}$ & 3.0 \\
\hline $\mathrm{CM}$ & $\begin{array}{l}\text { Regular reporting of outdoor tap } \\
\text { leaks }\end{array}$ & 3.0 \\
\hline $\mathrm{CM}$ & $\begin{array}{c}\text { Daily check that outdoor taps are } \\
\text { turned off }\end{array}$ & 3.0 \\
\hline $\mathrm{CL}$ & $\begin{array}{l}\text { Outdoor water restrictions in dry } \\
\text { season }\end{array}$ & 3.0 \\
\hline $\mathrm{CL}$ & School water education program & 3.0 \\
\hline $\mathrm{CM}$ & $\begin{array}{l}\text { Talking to other members of the } \\
\text { household about using less water }\end{array}$ & 2.9 \\
\hline $\mathrm{CL}$ & $\begin{array}{c}\text { A picture and explanation of your } \\
\text { household's water use }\end{array}$ & 2.8 \\
\hline $\mathrm{CL}$ & Social media announcements & 2.8 \\
\hline $\mathrm{CL}$ & $\begin{array}{l}\text { Inter-island competitions for lowest } \\
\text { water use }\end{array}$ & 2.8 \\
\hline $\mathrm{CL}$ & Rewarding low water use households & 2.8 \\
\hline $\mathrm{CL}$ & $\begin{array}{l}\text { Regular reports of your household } \\
\text { water use }\end{array}$ & 2.8 \\
\hline $\mathrm{CL}$ & $\begin{array}{l}\text { Permanent outdoor water } \\
\text { restrictions all year round }\end{array}$ & 2.8 \\
\hline $\mathrm{CL}$ & Installing a tap timer on outside tap & 2.7 \\
\hline $\mathrm{CL}$ & $\begin{array}{l}\text { Council notices about how much the } \\
\text { community is using }\end{array}$ & 2.7 \\
\hline $\mathrm{CL}$ & Shower timers with alarm & 2.7 \\
\hline $\mathrm{CL}$ & $\begin{array}{l}\text { Household alarms for high water use } \\
\text { (council is notified) }\end{array}$ & 2.7 \\
\hline $\mathrm{CL}$ & $\begin{array}{l}\text { Community education on water } \\
\text { savings }\end{array}$ & 2.6 \\
\hline $\mathrm{CL}$ & TV and radio announcements & 2.6 \\
\hline $\mathrm{CL}$ & Having a smart water meter installed & 2.5 \\
\hline $\mathrm{CM}$ & Using a tap timer on outside tap & 2.4 \\
\hline $\mathrm{CL}$ & Charging high water users & 2.3 \\
\hline $\mathrm{CL}$ & Recycling water for outdoor use & 2.3 \\
\hline $\mathrm{CL}$ & $\begin{array}{l}\text { Discussion of ways that your } \\
\text { household could save water }\end{array}$ & 2.3 \\
\hline $\mathrm{CM}$ & $\begin{array}{l}\text { Watering your garden / plants less } \\
\text { regularly }\end{array}$ & 2.3 \\
\hline $\mathrm{CL}$ & $\begin{array}{c}\text { Community workshops around the } \\
\text { benefits of water savings }\end{array}$ & 2.3 \\
\hline $\mathrm{CM}$ & $\begin{array}{l}\text { Public reporting of observed high } \\
\text { water users }\end{array}$ & 2.0 \\
\hline $\mathrm{CL}$ & $\begin{array}{l}\text { Better program for reporting and } \\
\text { repairing leaks }\end{array}$ & 1.7 \\
\hline
\end{tabular}


Thus, there is a need to improve the communications between council and community around water resource management overall, and the benefits of water efficient practices in particular. Without stronger communication and community engagement and involvement, there is the potential for limited long-term success of any CWDM program and consequently poor return on money, time and resources in this area of council expenditure.

Participants were generally very keen to work more closely with council though believed that it was council's responsibility to drive water conservation efforts initially with more community-based management strategies to follow once there had been stronger engagement and education from council about the "how, why and when" to reduce water consumption. In this respect, feedback and benchmarking, clearly acceptable and favoured by participants, would be a very useful tool.

The idea of engaging community Elders and Traditional Owners to take on a "water champion" role in the community, at the exclusion of TSIRC involvement, was not viewed favourably, as this role was seen firmly as council's responsibility. However, many participants agreed that sharing water stories with friends and family, and even as a school activity, as part of a Waterwise program, was an appropriate and effective way for the Elders to draw on Indigenous culture and knowledge transfer some of their stories of accessing and saving water to highlight the strengths of traditional water literacy in the community.

As recently discussed by Frangos et al (2020), the 'original water industry' of which Indigenous Australians were the custodians is a powerful and obvious pathway for transferring knowledge to future generations. Traditional education strategies which are embedded in water values and connection to land and spirit would not only be culturally respectful but would most likely increase the effectiveness of water demand management strategies.

\section{CONCLUSIONS}

With the goal of developing fit-for-purpose, -place and person water demand management strategies, researchers worked with the people of Kirirri, a small community in the Torres Straits, to better understand current water use and evaluate community-based demand management.

Positive, regular and consistent engagement and water conservation messaging is likely to yield more successful results in terms of sustained community engagement with
CWDM strategies. Based on responses from the two participant surveys and key informant interviews with community Elders, approaches such as ad-hoc water restriction notices without any visible enforcement, and punitive or negative messaging around water use, particularly singling out individuals, is unlikely to produce effective and long-term behaviour change around high water use activities.

Some key findings from this study can be used to support a broader framework for a community-based water demand management approach for remote Aboriginal and Torres Strait Islander communities (see Beal et al. 2019). For example, this work further confirms the importance of increasing reliance on community-based demand management approaches rather than externally led measures.

Engaging and encouraging the community (through water use feedback, benchmarking, community water use notices) and education and knowledge strategies, especially local water storytelling and traditional water literacy education, have greater potential to be locally supported than the more traditional enforcement (turning off mains water supplies and water restrictions) and economic (charging high water users) measures.

\section{ACKNOWLEDGEMENTS}

A big esso to all the people from Kirirri who participated in this study. Your time, stories and water wisdom were integral to the value of this work. Some Traditional Owners from Kiriri (who are also the co-authors on this paper) copresented this study at the International Water Association's Small Water and Wastewater Systems conference in Perth in December 2019. We would like to acknowledge the Australian Government for providing funding for this and Murdoch University for facilitating this initiative. 


\section{REFERENCES}

Aldirawi, S,. Souter, R,. Beal C.D. (2019) Barriers and opportunities for behavior change in managing high water demand in water scarce Indigenous communities: a Australian perspective. Journal of Water, Sanitation and Hygiene Research 9 (4):765-773.

Beal, C.D; Jackson, M.; Stewart, R.A.; Fielding, K., Miller, A., Tan, PL. (2019) Exploring community-based water management options for remote Australia. Final report for the Remote and Isolated Communities Essential Services Project, Griffith University, Brisbane, Qld. November, 2019. ISBN: 978-1-925455-93-9

https://www.griffith.edu.au/_data/assets/pdf_file/0036/9189 18/Remote-community-water-management-Beal-et-al-2019Final-Report-1.pdf

Beal, C.D., Jackson, M., Stewart, R.A., Rayment, C., Miller, A., 2018. Identifying and understanding the drivers of high water consumption in remote Australian Aboriginal and Torres Strait Island communities. J. Cleaner Prod. 172, 2425-2434.

Beal, CD., and Stewart, RA. (2014) Identifying Residential Water End-Uses Underpinning Peak Day and Peak Hour Demand. J. Water Resources Planning and Management, 140(7): 04014008.

Buergelt, P.T., Maypilama, E.L., McPhee, J., Dhurrkay, G., Nirrpuranydji, S., Mänydjurrpuy, S., Wunungmurra, M., Skinner, T., Lowell, A., Moss, S., 2017. Working Together with Remote Indigenous Communities to Facilitate Adapting to Using Energy Wisely: Barriers and Enablers. Energy Procedia 121, 262-269.

Frangos, M., Moggridge, B., Webb, T., Bassani, T., Duncan, P., 2020. The original water industry: Establishing a voice in the modern water industry. J. Aust. Water Assoc. 5 (2), 2020.

Hall, N.L., Creamer, S., Anders, W. et al. Water and health interlinkages of the sustainable development goals in remote Indigenous Australia. npj Clean Water 3, 10 (2020).

Hill, R., Grant, C., George, M., Robinson, C., Jackson, S., Abel, N., 2012. A typology of indigenous engagement in Australian environmental management: implications for knowledge integration and social-ecological system sustainability. Ecol. Soc. 17.
Jackson, M., Stewart, R.A., Beal, C.D. (2019a) Barriers and enablers to community-based sustainable water management: a study of practice in remote Indigenous Australia, Water in press, November 2019.

Jackson, M., Stewart, R.A., Fielding, K.S., Cochrane, J., Beal, C.D. (2019b) Collaborating for Sustainable Water and Energy Management: Assessment and Categorisation of Indigenous Involvement in Remote Australian Communities, Sustainability, 11 427-457.

Nguyen, K.A., Stewart, R.A., Zhang, H., Jones, C., 2015. Intelligent autonomous system for residential water end use classification: Autoflow. Applied Soft Computing 31, 118131.

Russell, S., Fielding, K., 2010. Water demand management research: A psychological perspective. Water Resour. Res. 46.

Tortajada, C., Joshi, Y.K., 2013. Water demand management in Singapore: Involving the public. Water Resour. Manag. 27 (8), 2729-2746.

Walton, A., Hume, M., 2011. Creating positive habits in water conservation: the case of the Queensland Water Commission and the Target 140 campaign. Int. J. Nonprofit Volunt. Sect. Mark. 16, 215-224 


\section{THE AUTHORS}

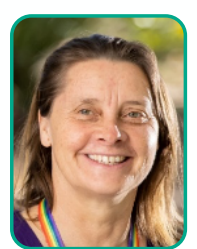

\section{Cara Beal}

Cara is an Associate Professor at the Cities Research Institute and School of Medicine, Griffith University, Brisbane and was the chief investigator of the project.

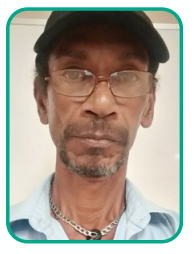

\section{Bernard Dorante}

Bernard is the Divisional Engineering Officer on Kirirri and assisted with many aspects of the project including the smart water meter installation, data collection and project participant engagement.

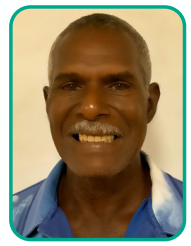

\section{Patrick Pearson}

Patrick is a senior Water Officer on Kirirri and assisted with many aspects of the project including the smart water meter installation data collection and project participant engagement.

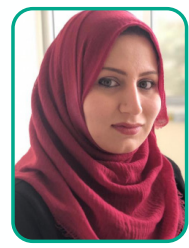

\section{Safaa Aldirawi}

Safaa is a WASH consultant in Gaza, Palestine Territories and conducted her final Masters project on barriers and enablers to water conservation and behaviour change on Kirirri.

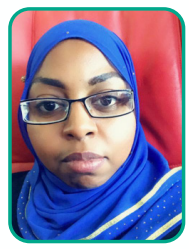

\section{Noora Abdallah}

Noora is a Water Engineer from Zanzibar, working with Zanzibar Water Authority, Tanzania and conducted her final Masters project on community water demand management on Kirirri. 